\title{
$\mathrm{PH} 100_{\text {debate }}$
}

a debate Repositorios y redes sociales académicas para la transferencia del conocimiento abierto

| coordina Remedios Melero Melero

\section{El conocimiento abierto ante las barreras de la evaluación institucional}

\author{
María Teresa García Ballesteros | Colección Fernández Rivero de Fotografía Antigua \\ URL de la contribución <www.iaph.es/revistaph/index.php/revistaph/article/view/4607>
}

El panorama de repositorios de acceso abierto interconectados y capaces no ya solo de difundir las investigaciones, sino además de proporcionar otros servicios como métricas, currículos... no es nada utópico ni aventurado; es real y las herramientas para conseguirlo están a nuestro alcance.

La necesidad de los repositorios es evidente. La capacidad de difusión de cualquier artículo, incluidos los publicados en las revistas más prestigiosas, se multiplica cuando un artículo se coloca en cualquiera de ellos, tanto en los casos de publicaciones de acceso abierto, que siempre son una ventaja en la difusión, como en las que no lo son, por varias razones:

$>$ En las publicaciones que no son de acceso abierto, la indexación de sus contenidos se circunscribe a las bases de datos de su área de conocimiento (por ejemplo, Medline en ciencias de la salud) o a aquellas otras que abarcan el mundo científico en su globalidad (como ScienceDirect).

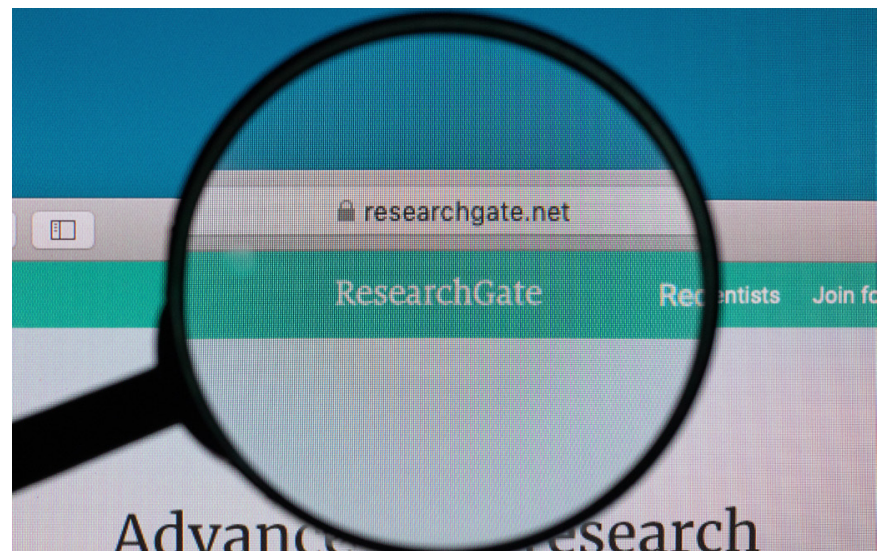

Muchos investigadores recurren a repositorios comerciales
> Algunas bases de datos son solo accesibles mediante suscripción y su consulta en muchos casos solo proporciona la referencia de los artículos y, en menor medida, el acceso a la totalidad del texto.

$>$ Los recolectores no penetran en estas bases de datos.

$>$ Las bases de datos y las revistas científicas, al contrario que muchos repositorios, no realizan acciones de difusión de sus contenidos.

El hecho de que muchos investigadores recurran a repositorios comerciales como Academia.edu o Researchgate es comprensible, en principio, por la facilidad de su manejo y la inmediatez de los resultados, en comparación con la forma en que funcionan muchos de nuestros repositorios institucionales, que precisan de la ayuda de un profesional capaz de responder a los requerimientos de estos programas. De hecho los bibliotecarios y documentalistas tienen ahí una de sus tareas, en la formación de aquellos que quieran hacer algún tipo de inmersión en documentación científica o simplemente como apoyo instrumental.

Por otro lado, cuando se les ha visto a los repositorios comerciales la intención de sacar provecho de nuestros depósitos, ya habíamos subido allí unos cuantos trabajos, ya que aprovecharon un momento de cuasi vacío... A ello van añadiendo, en forma de "servicio", vendernos la información sobre las interacciones que generan los propios artículos, consultas, citas, identidad de quienes se interesan por nuestros escritos... Contrarrestando, supongo, con su política de hacer una difusión activa de las publicaciones que van almacenando, esto último es un plus que se valora y que queda fuera del alcance de los investigadores. 
Las Humanidades lo tienen más difícil a la hora de encontrar repositorios (generales o especializados), fuera de los institucionales, para depositar las investigaciones.

Son destacables iniciativas como e-Lis que, a pesar de estar especializado en documentación, tiene una política abierta a otras áreas, o más recientemente Humanities Commons, que también realiza acciones de difusión de las aportaciones entre los miembros de su comunidad en función de los intereses de cada uno.

Así, si creemos que la publicación de las investigaciones debe tender a la máxima difusión y a la máxima facilidad de identificación de cada aportación, debemos contemplar también que la otra cara de la publicación científica es su objetivo de proporcionar méritos evaluables a sus autores, unos méritos que necesariamente han de encajar en los métodos diseñados por las políticas de evaluación de las instituciones. Y es aquí donde tenemos los escollos:

$>$ Realmente las prácticas de los investigadores dirigidas hacia la difusión de sus artículos no forman parte de los méritos a evaluar.

> Se prima publicar en revistas de prestigio, valoradas en función de un coeficiente matemático que no refleja la calidad real de las investigaciones.

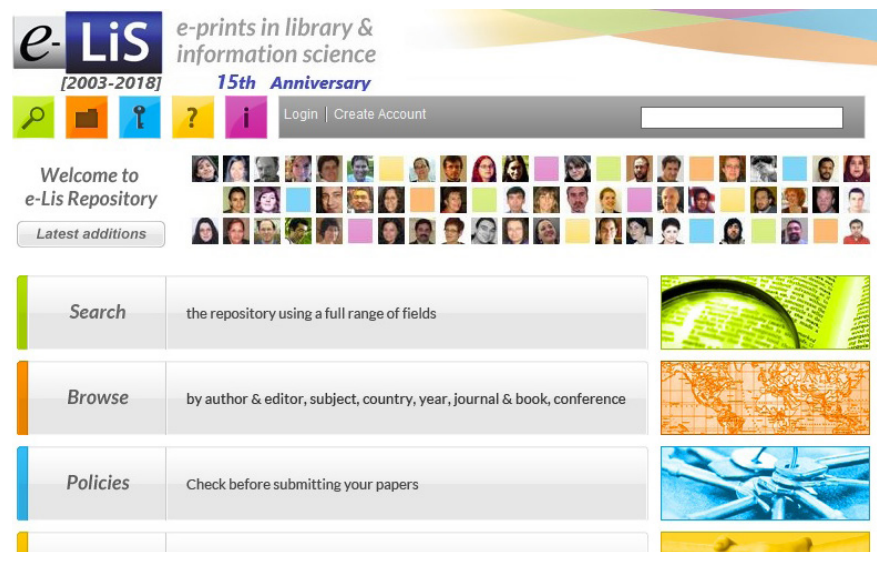

e-Lis tiene una política abierta a otras áreas, además de a la documentación
$>$ De forma que en muchas ocasiones son estas mismas "revistas de prestigio" las que limitan la capacidad de depósito de los artículos en los repositorios.

Se somete pues a los investigadores a una decisión contradictoria: publicar en revistas de acceso abierto en cualquiera de sus modalidades, que permitan la vía verde; o publicar en revistas que estén en la cabecera de los rankings de cada especialidad aunque impidan el depósito de los artículos en los repositorios.

Todo ello fruto de la incapacidad de las administraciones para resolver su propio dilema entre dejar que sea la empresa editorial quien realice las evaluaciones de la calidad de lo publicable, a cambio de la parte económica del pastel y en contra de la difusión total de la ciencia, o invertir las prácticas de evaluación, apostando por otras vías como la citación o la consulta de los artículos, o valorar además las prácticas de difusión e incluso de divulgación por parte de los investigadores.

Estas cuestiones llevan ya demasiados años sobre la mesa y ya va siendo hora de que toda la comunidad científica se implique en una solución exenta de contradicciones. 